\title{
US/UK collaboration proposed for breeder technology study
}

A US congressional commitee has approved funds for a joint US/UK study of the future development of liquid metal fast breeder reactor (LMFBR) technology, intended as part of the current programme to build such a reactor at Clinch River in Tennessee.

Precise details on how the money would be spent have yet to be determined. And whether the joint study manages to get off the ground depends largely on how much support can be generated for it in Congress and the administration.

However if the funding is approved the study would, according to US officials, provide a way of formalising the existing interchange of information between nuclear scientists in the two countries, perhaps leading to agreement on efforts to avoid duplication and to help in filling gaps in each other's programmes.

The joint study has been proposed by Energy Production Subcommittee of the House Committee on Science and Technology, which has consistently - and so far successfully - opposed President Carter's attempts since 1977 to terminate the Clinch River project.

Disagreeing with the President that fast breeder development should be delayed either because of the increased risks of nuclear proliferation or because of declining forecasts of energy demands, the subcommittee last year recommended $\$ 183$ million be spent in 1980 on the project, which had been dropped entirely from the Department of Energy's budget request.

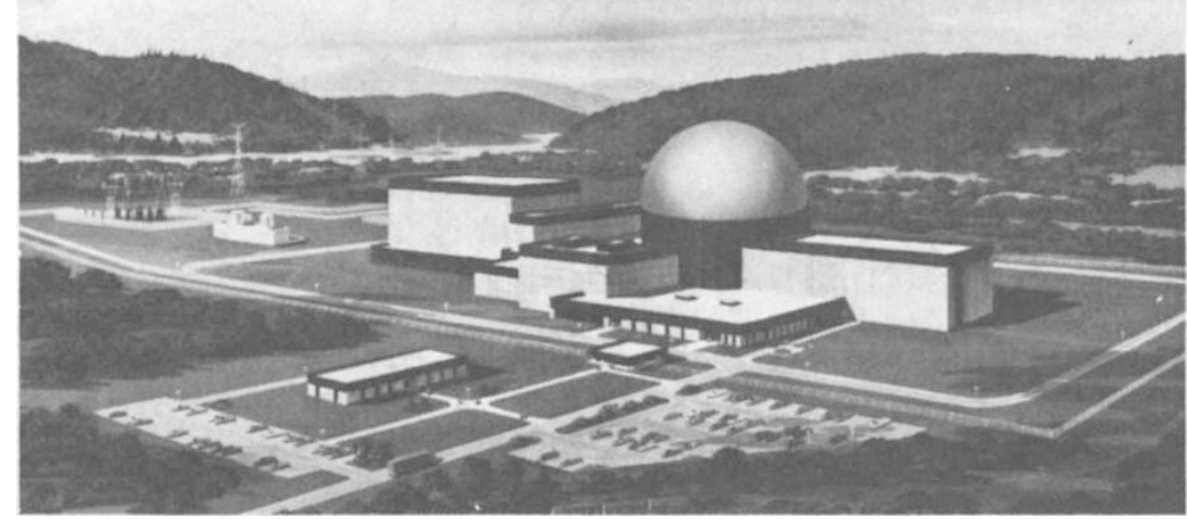

Clinch River: technical team to cooperate with UK scientists.

Congress subsequently approved spending $\$ 172$ million on the project.

This year, after the President had again recommended terminating the project in the budget for 1981, the subcommittee is proposing a budget of $\$ 155$ million. And of this, "up to $\$ 15$ million" would be for a joint US/UK study with particular emphasis on future fast breeder reactors.

Introducing an amendment to the DOE's budget request, Mrs Marilyn Lloyd Bouquard of Tennessee said that such an effort would be in line with the recommendations made in the final report of the International Nuclear Fuel Cycle Evaluation (INFCE). Ultimately, she said, it would lower the cost of fast breeders.

According to Mrs Bouquard, the proposed joint study would as far as possible draw upon the existing technical team, design information and data base of the Clinch River project, whose design is virtually finished but for which the DOE has not requested a construction permit.

A spokesman for the United Kingdom Atomic Energy Authority said that already agreement to exchange facilities with the US on fast breeder technology had been reached in September 1979: the UK will subject fuel assemblies to "gross abuses" in the US 'TREAT' test facility, while US researchers will have some access to the prototype fast reactor at Dounreay. But negotiations with the US, and France and Germany, for more extensive exchange on the scale envisaged by the congressional sub-committee were "at a very early stage", pending firm British commitment to a fast reactor policy.

\section{Panel urges research on tropics before forests disappear}

A substantial acceleration of the pace of compiling biological inventories of tropical plants and animals, and a four to five-fold increase in the number of appropriately trained taxonomists to help achieve this, have been recommended in a report on tropical biology by a panel of the National Academy of Sciences. The report, shortly to be published in Washington, warns of the increasingly rapid disappearance of the world's forests.

The panel also lists a number of areas of tropical forests, including the coastal forests of Ecuador, eastern and southern Brazilian Amazonia, and western and southern Cameroon, which it says should receive particular attention by taxonomists over the next 5 to 10 years, since they contain little-known biota in immediate danger of extinction.

And it reconımends that a comprehensive laboratory should be established in Puerto Rico as a centre for research and training in tropical physiological plant ecology.

"The creation of such a laboratory appears to be critical for the establishment of a field of investigation that is poorly developed in the tropics. Such investigation appears to offer a great deal both in scientific and societal rewards" the report says.

The report was prepared by the Committee on Research Priorities in Tropical Biology of the Academy's National Research Council, chaired by Dr Peter $\mathbf{H}$ Raven of Missouri Botanical Gardens, St Louis, Missouri.

Speaking in Washington last week, Dr Raven pointed out that less than $10 \%$ of the Earth's estimated four to five million species have yet been properly classified, but that while scientific knowledge of tropical ecosystems was virtually nonexistent, these areas were being destroyed by population pressures and other demands at an alarming rate.

"I am convinced that $95 \%$ of the forests will be converted within 25 to 30 years", said Dr Raven, whose panel predicted that by the close of the century the only extensive areas of undisturbed forest remaining would probably be chiefly those in the western Brazilian Amazonia and in Central Africa. However even those, it says, will probably only persist "for a few more decades".

Dr Raven's conclusions were supported by Dr Norman Myers, author of a study Conservation of Tropical Moist Forests commisioned by the panel, which provides a detailed account of the areas currently under threat.

According to Dr Myers, about three quarters of the tropical forests that have already been lost through the actions of millions of forest farmers over the world, who have been able to gain access to the heart of forested areas by using logging trails.

The Academy report warns that if the destruction of the forests continues at the present rate until the next century, the result will be not only widespread human misery and "alterations to the course of evolution", but also the loss of potentially useful knowledge about plant and animal species that might have been used to mitigate some of the consequences of such development.

"This knowledge is therefore not only of theoretical importance, but has critical application of benefit to human welfare, both in the tropical countries themselves and throughout the world. If tropical research is allowed to continue at its present level, it will contribute only in a minor way to the solution of the human and scientific problems to which we have alluded" the report says. David Dickson 